\title{
VARIASI PEMBAYARAN ANUITAS DENGAN POLA DERET ARITMATIKA
}

\author{
Devni Prima Sari \\ Jurusan Matematika Universitas Negeri Padang, Indonesia \\ email: devniprimasari@yahoo.com
}

\begin{abstract}
Abstrak. Anuitas adalah rangkaian pembayaran atau penerimaan dalam jumlah tertentu yang dilakukan secara berkala pada jangka waktu tertentu. Konsep anuitas dapat dimulai dengan ketersedian sejumlah dana yang digunakan untuk membayar angsuran dalam suatu jangka waktu sampai dana tersebut habis. Pembayaran anuitas biasanya dilakukan dalam jumlah tetap setiap tahunnya. Oleh karena itu penulis mencoba menganalisa secara matematika mengenai nilai sekarang dan nilai akhir dari pembayaran anuitas yang dilakukan berbeda setiap tahunnya, baik pembayaran naik maupun turun dengan skema pembayaran anuitas mengikuti pola deret aritmatika. Pembayaran anuitas yang seperti ini bisa dijadikan pilihan bagi para annuitant.
\end{abstract}

Kata kunci: Anuitas, anuitas naik, anuitas turun

\section{A. PENDAHULUAN}

Anuitas adalah serangkaian pembayaran yang dilakukan pada jangka waktu tertentu (Kellison,1991). Anuitas berasal dari bahasa Latin annus yang berarti tahun. Akan tetapi seiring dengan berjalannya waktu kata anuitas juga mencakup pembayaran yang dilakukan pada interval waktu yang lain, seperti pembayaran bulanan, tiga bulanan, dan seterusnya (Vaaler, 2008). Anuitas bukan barang baru lagi dalam kehidupan. Seseorang yang menyewa rumah, seseorang yang membeli motor secara kredit, atau pun uang tabungan di bank yang setiap bulan mendapatkan bunga, dan lain-lain.

Pembayaran anuitas dapat dilakukan pada awal periode dan dapat pula dilakukan pada akhir periode. Jika pembayaran terjadi pada akhir setiap periode, disebut sebagai anuitas akhir (immediate annuity) Sebaliknya, jika pembayaran terjadi pada awal setiap periode, disebut sebagai anuitas awal (due annuity). Selain perbedaan waktu penerimaan atau pembayaran, kedua jenis anuitas tersebut juga dibedakan dengan sedikit modifikasi rumus, seperti anuitas biasa dimana pembayaran tiap periode selalu sama, dan anuitas dengan ragam pembayaran dimana pembayaran tiap periode nilainya tidak sama. Pada pembahasan anuitas terdapat dua istilah penting yaitu nilai tunai (present value) yaitu nilai seluruh pembayaran jika anuitas dibayar sekaligus dalam satu kali dan nilai akhir (cumulative value) yaitu jumlah seluruh pembayaran pada suatu waktu di kemudian hari. 
Jika menggunakan ragam pembayaran deret aritmatika maka akan menyebabkan kenaikan (increasing) maupun penurunan (decreasing) jumlah uang yang harus dibayarkan tiap periode waktunya, dimana kenaikan maupun penurunan tersebut sangat bergantung pada tingkat bunga yang digunakan tiap periode waktu pembayaran. Jika menggunakan tingkat bunga efektif tetap tiap periode waktu pembayaran maka anuitas tiap periode akan naik atau turun secara konstan. (Vaaler dan Daniel, 2008).

\section{B. METODE PENELITIAN}

Penelitian yang dilakukan merupakan penelitian dasar (teoritis), dengan menganalisis teoriteori yang relevan terhadap permasalahan yang dibahas berdasarkan pada kajian kepustakaan. Dalam meninjau permasalahan yang dihadapi, langkah kerja yang dilakukan adalah mengumpulkan dan mengaitkan teori-teori yang relevan dengan permasalahan penentuan nilai sekarang dan nilai akhir dari anuitas naik dan anuitas turun.

\section{HASIL DAN PEMBAHASAN}

\section{Anuitas Akhir dengan Pembayaran Berubah}

\section{Bentuk Umum Anuitas Akhir Naik}

Seperti yang dijelaskan oleh Kellison, anuitas akhir dibayarkan selama n tahun dengan pembayaran pertama sebesar $\mathrm{G}$ dan masing-masing pembayaran berikutnya meningkat sebesar H, di mana semua pembayaran dilakukan pada akhir tahun. Gambar garis waktu di bawah menggambarkan kejadian di atas

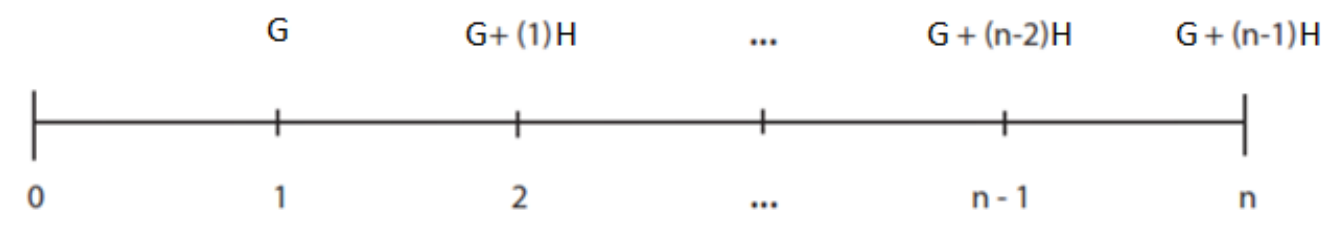

Gambar 1

Nilai sekarang (saat $\mathrm{t}=0$ ) dari anuitas akhir, di mana tingkat bunga efektif adalah $\mathrm{i}$, dihitung sebagai berikut, 


$$
\begin{aligned}
& P V_{0}=[G] v^{1}+[G+H] v^{2}+[G+2 H] v^{3}+\cdots+[G+(n-2) \cdot H] v^{n-1}+[G+(n-1) \cdot H] v^{n} \\
& =G\left(v^{1}+v^{2}+v^{3}+\cdots+v^{n-1}+v^{n}\right)+H\left[v^{2}+2 v^{3}+\cdots+(n-2) v^{n-1}+(n-1) v^{n}\right] \\
& =G\left(v^{1}+v^{2}+v^{3}+\cdots+v^{n-1}+v^{n}\right)+H v^{2}\left[1+2 v+\cdots+(n-2) v^{n-3}+(n-1) v^{n-2}\right] \\
& =G\left(v^{1}+v^{2}+v^{3}+\cdots+v^{n-1}+v^{n}\right)+H \cdot v^{2} \frac{d}{d v}\left[1+v+\cdots+v^{n-2}+v^{n-1}\right] \\
& P V_{0}=G \cdot a_{\overrightarrow{n i}}+H \cdot v^{2} \frac{d}{d v}\left[\ddot{a}_{\overrightarrow{n i}}\right] \\
& =G \cdot a_{\bar{n} i}+H \cdot v^{2} \frac{d}{d v}\left[\frac{1-v^{n}}{1-v}\right] \\
& =G a_{n: i}+H v^{2}\left[\frac{(1-v) \cdot\left(-n v^{n-1}\right)-\left(1-v^{n}\right) \cdot(-1)}{(1-v)^{2}}\right] \\
& =G \cdot a_{n i}+\frac{H}{(1+i)^{2}}\left[\frac{-n v^{n}\left(v^{-1}-1\right)+\left(1-v^{n}\right)}{(i / 1+i)^{2}}\right] \\
& =G \cdot a_{n i}+H\left[\frac{\left(1-v^{n}\right)-n v^{n}\left(v^{-1}-1\right)}{i^{2}}\right] \\
& =G \cdot a_{n i}+H\left[\frac{\left(1-v^{n}\right)-n v^{n}(1+i-1)}{i^{2}}\right] \\
& =G \cdot a_{n i}+H\left[\frac{\frac{\left(1-v^{n}\right)}{i}-\frac{n v^{n}(i)}{i}}{i}\right] \\
& =G \cdot a_{\overrightarrow{n i}}+H\left[\frac{a_{n i}-n v^{n}}{i}\right]
\end{aligned}
$$

Nilai akumulasi (saat $\mathrm{t}=\mathrm{n}$ ) dari anuitas akhir, di mana tingkat bunga efektif adalah $\mathrm{i}$, bias dihitung dengan menggunakan pendekatan yang sama seperti di atas atau dihitung dengan menggunakan prinsip dasar di mana nilai akumulasi sama dengan nilai sekarang dikali dengan $(1+i)^{n}$ : 


$$
\begin{aligned}
& F V_{n}=P V_{0} \cdot(1+i)^{n} \\
& =\left(G \cdot a_{n i}+H\left[\frac{a_{n i}-n v^{n}}{i}\right]\right) \cdot(1+i)^{n} \\
& =G \cdot a_{n i} \cdot(1+i)^{n}+H\left[\frac{a_{n i} \cdot(1+i)^{n}-n v^{n} \cdot(1+i)^{n}}{i}\right] \\
& =G . s_{\overrightarrow{n i}}+H\left[\frac{s_{\overrightarrow{n i}}-n}{i}\right]
\end{aligned}
$$

\section{Bentuk Khusus Anuitas Akhir Naik}

Misalkan $G=1$ dan $H=1$. Dalam kasus ini, pembayaran mulai dari 1 dan meningkat 1 setiap tahun sampai pembayaran akhir dibuat pada waktu $\mathrm{n}$.

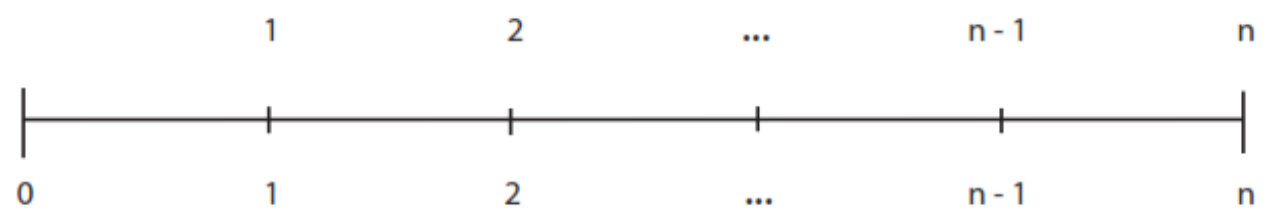

Gambar 2

Nilai sekarang (saat $\mathrm{t}=0$ ) dari anuitas akhir naik, di mana tingkat bunga efektif tahunan $\mathrm{i}$, dinyatakan sebagai $(I a)_{n i}$ dan dihitung sebagai berikut:

$$
\begin{aligned}
(I a)_{n i} & =(1) \cdot a_{n i}+(1) \cdot\left[\frac{a_{n i}-n v^{n}}{i}\right] \\
& =\frac{1-v^{n}}{i}+\frac{a_{n i}-n v^{n}}{i} \\
& =\frac{1-v^{n}+a_{n i}-n v^{n}}{i} \\
& =\frac{\ddot{a}_{n i}-n v^{n}}{i}
\end{aligned}
$$

Nilai akumulasi (saat $\mathrm{t}=\mathrm{n}$ ) dari anuitas akhir naik, di mana tingkat bunga efektif tahunan $\mathrm{i}$,

dinyatakan sebagai $(I S)_{\overline{n i}}$ dan dapat dihitung dengan menggunakan pendekatan umum yang sama seperti di atas, alternatif lain, dengan menggunakan prinsip dasar di mana nilai akumulasi sama dengan dengan nilai sekarang dikali dengan $(1+i)^{n}$ : 


$$
\begin{aligned}
(I s)_{\overrightarrow{n i}} & =(I a)_{n i} \cdot(1+i)^{n} \\
& =\left(\frac{\ddot{a}_{\overrightarrow{n i}}-n v^{n}}{i}\right)(1+i)^{n} \\
& =\frac{\ddot{a}_{\vec{n} i} \cdot(1+i)^{n}-n v^{n} \cdot(1+i)^{n}}{i} \\
& =\frac{\ddot{s}_{\overrightarrow{n i}}-n}{i}
\end{aligned}
$$

\section{Bentuk Khusus Anuitas Akhir Turun}

Misalkan $\mathrm{P}=\mathrm{n}$ dan $\mathrm{Q}=-1$. Dalam kasus ini, pembayaran mulai dari $\mathrm{n}$ dan mengalami penurunan sebesar 1 setiap tahun sampai pembayaran terakhir dibuat pada waktu $\mathrm{n}$.

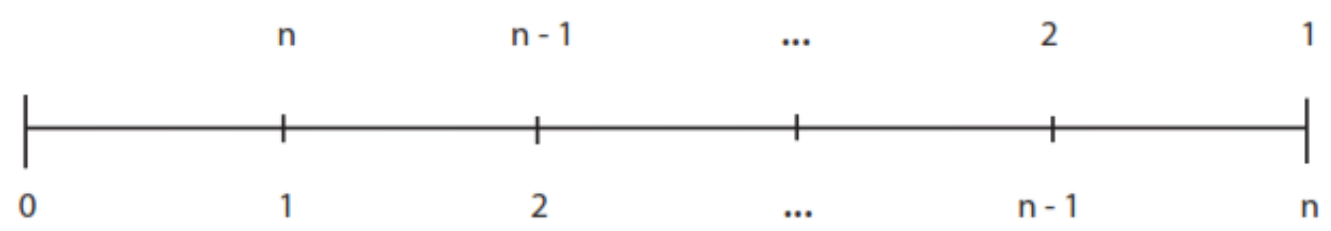

Gambar 3

Nilai sekarang (saat $\mathrm{t}=0$ dari anuitas akhir turun, di mana tingkat bunga efektif tahunan $\mathrm{i}$, dinyatakan sebagai $(D a)_{\overline{n i}}$ dan dihitung sebagai berikut:

$$
\begin{aligned}
(D a)_{n i} & =(n) \cdot a_{n i}-(1) \cdot\left[\frac{a_{n i}-n v^{n}}{i}\right] \\
& =n \cdot \frac{1-v^{n}}{i}-\frac{a_{n i}-n v^{n}}{i} \\
& =\frac{n-n v^{n}-a_{n i}+n v^{n}}{i} \\
& =\frac{n-a_{n i}}{i}
\end{aligned}
$$

Nilai akumulasi (saat $\mathrm{t}=\mathrm{n}$ ) dari anuitas akhir turun, di mana tingkat bunga efektif tahunan

i, dinyatakan sebagai $(D s)_{\overline{n i}}$ dan dapat dihitung dengan menggunakan pendekatan umum yang sama seperti di atas, alternatif lain, dengan menggunakan prinsip dasar di mana nilai akumulasi sama dengan dengan nilai sekarang dikali dengan $(1+i)^{n}$ : 


$$
\begin{aligned}
(D s)_{\overrightarrow{n i}} & =(D a)_{\vec{n} i} \cdot(1+i)^{n} \\
& =\left(\frac{n-a_{\vec{n} i}}{i}\right) \cdot(1+i)^{n} \\
& =\frac{n \cdot(1+i)^{n}-s_{\overrightarrow{n i}}}{i}
\end{aligned}
$$

\section{Anuitas Awal dengan Pembayaran Berubah}

\section{Bentuk Umum Anuitas Awal Naik}

Seperti yang dijelaskan oleh Kellison, anuitas awal dibayarkan selama n tahun dengan pembayaran pertama sebesar $\mathrm{G}$ dan masing-masing pembayaran berikutnya meningkat sebesar $\mathrm{H}$, di mana semua pembayaran dilakukan pada awal tahun. Gambar garis waktu di bawah menggambarkan kejadian di atas.

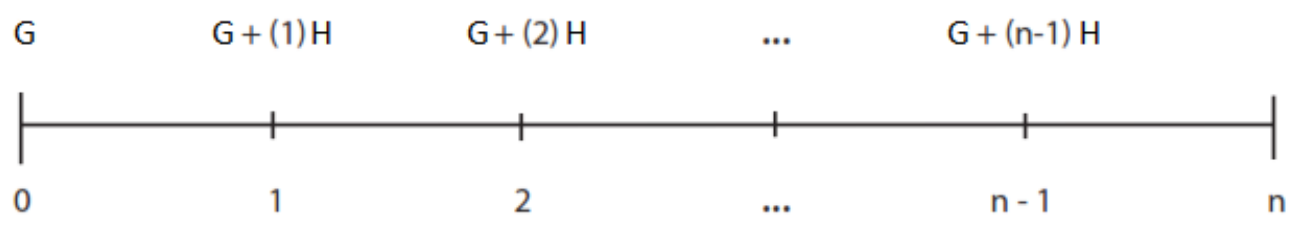

Gambar 4

Nilai sekarang (saat $\mathrm{t}=0$ ) dari anuitas awal, di mana tingkat bunga efektif adalah $\mathrm{i}$, dihitung sebagai berikut,

$$
\begin{aligned}
& P V_{0}=[G] v^{0}+[G+H] v^{1}+[G+2 H] v^{1}+\cdots+[G+(n-2) \cdot H] v^{n-2}+[G+(n-1) \cdot H] v^{n-1} \\
& =G\left(1+v^{1}+v^{2}+\cdots+v^{n-2}+v^{n-1}\right)+H\left[v^{1}+2 v^{2}+\cdots+(n-2) v^{n-2}+(n-1) v^{n-1}\right] \\
& =G\left(1+v^{1}+v^{2}+\cdots+v^{n-2}+v^{n-1}\right)+H \cdot v\left[1+2 v+\cdots+(n-2) v^{n-3}+(n-1) v^{n-2}\right] \\
& =G\left(1+v^{1}+v^{2}+\cdots+v^{n-2}+v^{n-1}\right)+H \cdot v \frac{d}{d v}\left[1+v+\cdots+v^{n-2}+v^{n-1}\right] \\
& =G \cdot \ddot{a}_{n i}+H \cdot v \frac{d}{d v}\left[\ddot{a}_{n i}\right] \\
& =G . \ddot{a}_{\vec{n} i}+H \cdot v \frac{d}{d v}\left[\frac{1-v^{n}}{1-v}\right]
\end{aligned}
$$




$$
\begin{aligned}
P V_{0} & =G \cdot \ddot{a}_{n i}+H v\left[\frac{(1-v) \cdot\left(-n v^{n-1}\right)-\left(1-v^{n}\right) \cdot(-1)}{(1-v)^{2}}\right] \\
& =G \cdot \ddot{a}_{n i}+\frac{H}{(1+i)}\left[\frac{-n v^{n}\left(v^{-1}-1\right)+\left(1-v^{n}\right)}{(i / 1+i)^{2}}\right] \\
& =G \cdot \ddot{a}_{\overrightarrow{n i}}+H\left[\frac{\left(1-v^{n}\right)-n v^{n}(1+i-1)}{i^{2}}\right] \cdot(1+i) \\
& =G \cdot \ddot{a}_{\overrightarrow{n i}}+H\left[\frac{\left(1-v^{n}\right)-n v^{n}\left(v^{-1}-1\right)}{i^{2}}\right] \cdot(1+i) \\
& =G \cdot \ddot{a}_{\vec{n} i}+H\left[\frac{\left(1-v^{n}\right)}{i}-\frac{n v^{n}(i)}{i}\right] \cdot(1+i) \\
& =G \cdot \ddot{a}_{\vec{n} i}+H\left[\frac{a_{n i}-n v^{n}}{i}\right] \cdot(1+i) \\
& =G \cdot \ddot{a}_{\vec{n} i}+H\left[\frac{a_{\vec{n} i}-n v^{n}}{d}\right]
\end{aligned}
$$

Nilai akumulasi (saat $\mathrm{t}=\mathrm{n}$ ) dari anuitas awal, di mana tingkat bunga efektif adalah $\mathrm{i}$, bias dihitung dengan menggunakan pendekatan yang sama seperti di atas atau dihitung dengan menggunakan prinsip dasar di mana nilai akumulasi sama dengan nilai sekarang dikali dengan $(1+i)^{n}$ :

$$
\begin{aligned}
F V_{n} & =P V_{0} \cdot(1+i)^{n} \\
& =\left(G \cdot \ddot{a}_{\overrightarrow{n i}}+H\left[\frac{a_{\overrightarrow{n i}}-n v^{n}}{d}\right]\right) \cdot(1+i)^{n} \\
& =G \cdot \ddot{a}_{\overrightarrow{n i}} \cdot(1+i)^{n}+H\left[\frac{a_{n i} \cdot(1+i)^{n}-n v^{n} \cdot(1+i)^{n}}{d}\right] \\
& =G . \ddot{s}_{\overrightarrow{n i}}+H\left[\frac{s_{\vec{n} i}-n}{d}\right]
\end{aligned}
$$

\section{Bentuk Khusus Anuitas Awal Naik}

Misalkan $G=1$ dan $H=1$. Dalam kasus ini, pembayaran mulai dari 1 dan meningkat 1 setiap tahun sampai pembayaran terakhir dibuat pada waktu $n-1$. 


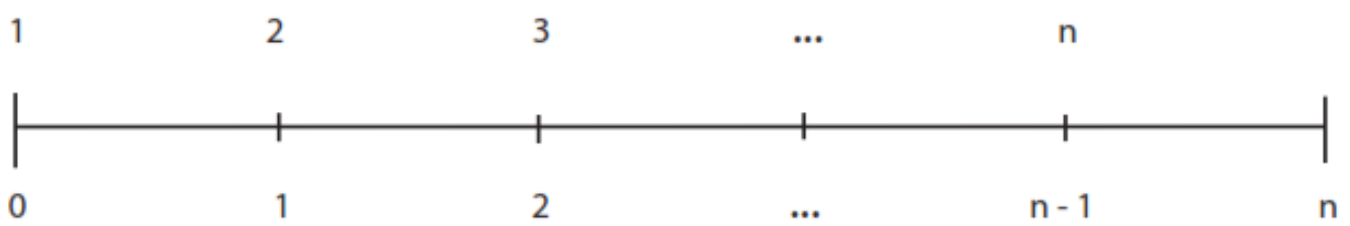

Gambar 5

Nilai sekarang (saat $\mathrm{t}=0$ ) dari anuitas awal naik, di mana tingkat bunga efektif tahunan $\mathrm{i}$, dinyatakan sebagai $(I \ddot{a})_{\overline{n i}}$ dan dihitung sebagai berikut:

$$
\begin{aligned}
(I \ddot{a})_{\overrightarrow{n i}} & =(1) \cdot \ddot{a}_{n i}+(1) \cdot\left[\frac{a_{n i}-n v^{n}}{d}\right] \\
& =\frac{1-v^{n}}{d}+\frac{a_{\overrightarrow{n i}}-n v^{n}}{d} \\
& =\frac{1-v^{n}+a_{n i}-n v^{n}}{d} \\
& =\frac{\ddot{a}_{n i}-n v^{n}}{d}
\end{aligned}
$$

Nilai akumulasi (saat $\mathrm{t}=\mathrm{n}$ ) dari anuitas awal naik, di mana tingkat bunga efektif tahunan $\mathrm{i}$, dinyatakan sebagai $(I s)_{n i}$ dan dapat dihitung dengan menggunakan pendekatan umum yang sama seperti di atas, alternatif lain, dengan menggunakan prinsip dasar di mana nilai akumulasi sama dengan dengan nilai sekarang dikali dengan $(1+i)^{n}$,

$$
\begin{aligned}
(I \ddot{s})_{\overrightarrow{n i}} & =(I \ddot{a})_{\overrightarrow{n i}} \cdot(1+i)^{n} \\
& =\left(\frac{\ddot{a}_{\overrightarrow{n i}}-n v^{n}}{d}\right)(1+i)^{n} \\
& =\frac{\ddot{a}_{\vec{n} i} \cdot(1+i)^{n}-n v^{n} \cdot(1+i)^{n}}{d} \\
& =\frac{\ddot{s}_{\overrightarrow{n i}}-n}{d}
\end{aligned}
$$

\section{Bentuk Khusus Anuitas Awal Turun}

Misalkan $\mathrm{P}=\mathrm{n}$ dan $\mathrm{Q}=-1$. Dalam kasus ini, pembayaran mulai dari $\mathrm{n}$ dan mengalami penurunan sebesar 1 setiap tahun sampai pembayaran terakhir dibuat pada waktu $\mathrm{n}-1$.

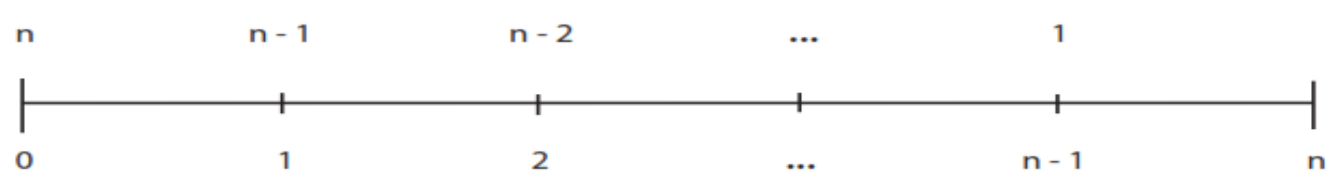

Gambar 6 
Nilai sekarang (saat $\mathrm{t}=0$ dari anuitas awal turun, di mana tingkat bunga efektif tahunan $\mathrm{i}$, dinyatakan sebagai $(D \ddot{a})_{n i}$ dan dihitung sebagai berikut:

$$
\begin{aligned}
(D \ddot{a})_{\overrightarrow{n i}} & =(n) \cdot \ddot{a}_{\overrightarrow{n i}}-(1) \cdot\left[\frac{a_{\vec{n} i}-n v^{n}}{d}\right] \\
& =n \cdot \frac{1-v^{n}}{d}-\frac{a_{\eta i}-n v^{n}}{d} \\
& =\frac{n-n v^{n}-a_{\vec{n} i}+n v^{n}}{d} \\
& =\frac{n-a_{n i}}{d}
\end{aligned}
$$

Nilai akumulasi (saat $\mathrm{t}=\mathrm{n}$ ) dari anuitas awal turun, di mana tingkat bunga efektif tahunan $\mathrm{i}$, dinyatakan sebagai $(D \ddot{s})_{\overparen{n i}}$ dan dapat dihitung dengan menggunakan pendekatan umum yang sama seperti di atas, alternatif lain, dengan menggunakan prinsip dasar di mana nilai akumulasi sama dengan dengan nilai sekarang dikali dengan $(1+i)^{n}$ :

$$
\begin{aligned}
(D \ddot{s})_{\overrightarrow{n i}} & =(D \ddot{a})_{n \overrightarrow{n i}} \cdot(1+i)^{n} \\
& =\left(\frac{n-a_{\overrightarrow{n i}}}{d}\right) \cdot(1+i)^{n} \\
& =\frac{n \cdot(1+i)^{n}-s_{\vec{n} i}}{d}
\end{aligned}
$$

\section{KESIMPULAN DAN SARAN}

Dari pembahasan yang telah dilakukan dapat disimpulkan bahwa:

Formulasi nilai sekarang dan nilai akhir anuitas akhir dengan pembayaran berubah

Bentuk umum anuitas akhir naik

$$
\begin{aligned}
& P V_{0}=G \cdot a_{\overrightarrow{n i}}+H\left[\frac{a_{n i}-n v^{n}}{i}\right] \\
& F V_{n}=G \cdot s_{n i}+H\left[\frac{s_{\vec{n} i}-n}{i}\right]
\end{aligned}
$$

Bentuk khusus anuitas akhir naik

$$
(I a)_{n i}=\frac{\ddot{a}_{n i}-n v^{n}}{i}
$$


$(I s)_{n i}=\frac{\ddot{s}_{\overline{n i}}-n}{i}$

Bentuk khusus anuitas akhir turun

$$
\begin{aligned}
& (D a)_{n i}=\frac{n-a_{\vec{n} i}}{i} \\
& (D s)_{n i}=\frac{n \cdot(1+i)^{n}-s_{\overrightarrow{n i}}}{i}
\end{aligned}
$$

Formulasi nilai sekarang dan nilai akhir anuitas awal dengan pembayaran berubah

Bentuk umum anuitas awal naik

$$
\begin{aligned}
& P V_{0}=G . \ddot{a}_{\vec{n} i}+H\left[\frac{a_{n i}-n v^{n}}{d}\right] \\
& F V_{n}=G . \ddot{s}_{\ddot{n} i}+H\left[\frac{s_{\vec{n} i}-n}{d}\right]
\end{aligned}
$$

Bentuk khusus anuitas awal naik

$$
\begin{aligned}
& (I \ddot{a})_{n i}=\frac{\ddot{a}_{n i}-n v^{n}}{d} \\
& (I \ddot{s})_{n i}=\frac{\ddot{s}_{\ddot{n i}}-n}{d}
\end{aligned}
$$

Bentuk khusus anuitas awal turun

$$
\begin{aligned}
& (D \ddot{a})_{n i}=\frac{n-a_{\overrightarrow{n i}}}{d} \\
& (D \ddot{s})_{\overline{n i}}=\frac{n \cdot(1+i)^{n}-s_{\overrightarrow{n i}}}{d}
\end{aligned}
$$

\section{DAFTAR PUSTAKA}

1. Bowers, Newton L. et al. 1997. Actuarial Mathematics. The Society of Actuaries.

2. Futami, Takashi. 1992. Matematika Asuransi Jiwa Bagian I. Jakarta : Rekaprint Utama

3. Kellison, Stephen G. 2009. The Theory of Interest (3rd Edition). New York : Mc Graw Hill.

4. Vaaler, L. J. F. dan Daniel, J.W. 2008. Mathematical Interest Theory (2nd Edition). Washington.DC: Pearson Prentice Hall. 